\title{
A CONFIGURAÇÃO DO CAMPO DA EDUCAÇÃO PROFISSIONAL NO BRASIL
}

\author{
O. M. MEDEIROS NETA \\ Universidade Federal do Rio Grande do Norte \\ olivianeta@gmail.com
}

Artigo submetido em agosto/2016 e aceito em setembro/2016

DOI: $10.15628 /$ holos.2016.4947

\section{RESUMO}

O objetivo desse texto é o de debater sobre a configuração do campo da educação profissional (EP), atentando às inter-relações desse campo e aos desafios a ele concernentes. Para tanto, mapeamos a produção sobre EP no Portal Capes, sendo consideradas as publicações disponíveis no Portal até o ano de 2014 e o termo educação profissional, com a utilização das aspas. Para a compreensão da configuração do campo de produção do conhecimento em Educação Profissional, nos aproximamos do entendimento de campo científico de Bourdieu. A partir das análises, podemos considerar que o campo da EP no Brasil vem se configurando pelas inter-relações de temáticas como educação e trabalho na leitura da EP como modalidade de ensino e espaço de disputas políticas. E mais, o campo da EP no Brasil vem ganhando novos contornos com objetos e temas provenientes das transformações históricas vinculadas as políticas públicas voltadas à EP.

PALAVRAS-CHAVE: Educação profissional, Produção do conhecimento, Campo científico, Brasil.

\section{THE FIELD CONFIGURATION OF VOCATIONAL EDUCATION IN BRAZIL}

\begin{abstract}
The aim of this paper is to discuss the setting up of vocational education field, considering the interrelationships of the field and the challenges to it concerning. To this end, we map the production of vocation education in Portal Capes, considering the publications available on the Portal by the year 2014 and the term professional education, with the use of quotation marks. For understanding the configuration of the Vocational Education in knowledge of the field, we
\end{abstract}

approach the scientific field of understanding of Bourdieu. From the analysis, we can consider that the field of vocation education in Brazil has been setting the thematic interrelations as education and work on reading the vocation education as a teaching mode and space of political disputes. Moreover, the field of vocation education in Brazil is gaining new contours with objects and themes from the historical transformations related public policies for the vocation education.

KEYWORDS: Professional education, Knowledge production, Scientific field, Brazil. 
Qual a nossa relação com a Educação Profissional? Seria pela dimensão do ensino? Da pesquisa? Ou mesmo da extensão? Em um texto como esse, torna-se difícil uma dissociação. Mas, hoje, peço licença para dialogar com vocês a partir de uma dimensão, a da pesquisa, com o objetivo de debater sobre a configuração do campo da educação profissional, atentando às inter-relações desse campo e aos desafios a ele concernentes.

As discussões aqui apresentadas são decorrentes das ações de investigação do projeto de pesquisa "O campo da Educação Profissional e a produção e difusão do conhecimento" financiado pela Pró-reitoria de Pesquisa e Inovação do Instituto Federal de Educação, Ciência e Tecnologia do Rio Grande do Norte (IFRN), sob minha coordenação, e das pesquisas em andamento da mestranda Vanessa Cavalcante (PPGEP/IFRN).

Para a compreensão da configuração do campo de produção do conhecimento em Educação Profissional, nos aproximamos do entendimento de campo científico de Bourdieu (1983) que o apresenta como espaço social, um locus de relações de força e disputas, que visa beneficiar interesses específicos dos participantes deste campo. Pois, a capacidade de "produzir ciência", por parte de um determinado indivíduo ou grupo, está agregada a um determinado poder social.

E, associado ao entendimento de campo científico usamos o de configuração, conforme Norbert Elias (1994). Pois entendemos que as configurações são formadas por grupos interdependentes (no caso, grupos de pesquisadores e suas conexões institucionais), organizados coletivamente e não por indivíduos singulares. Assim, a configuração é sempre um espaço de síntese, sempre provisória, do movimento dialético da realidade

Quando vamos às leituras sobre a $E P$, grande parte dessas leituras remete às políticas públicas à $E P$, às práticas pedagógicas e currículo da Educação Básica integrada à $E P$, à formação de professores e seus desafios.

Estaria nesse conjunto de temáticas as respostas à indagação: como se constitui o campo da educação profissional no Brasil? Se sim, significa que esses são os temas com maior investimento e presença na produção dos pesquisadores de EP no Brasil.

Como isso, podemos inferir que o campo da Educação Profissional no Brasil foi se constituindo a partir de estudos que remetiam as variáveis que cortam a EP como modalidade de ensino. Assim, remetemo-nos a hipótese de que a produção do conhecimento no campo se confunde com o histórico da Educação Profissional no Brasil e com a busca pela compreensão da dualidade estrutural concernente a esse tipo de educação.

Então, consideramos que, muitas vezes, nos preocupamos com o que está circunscrito a EP como modalidade, mas não nos desafiamos a demarcar conceitualmente a EP. Nesses termos, qual o nosso entendimento sobre EP? Silvia Manfredi, no investimento de demarcar o campo expressou:

Educação Profissional é um campo de disputa e de negociação entre os diferentes segmentos e grupos que compõem uma sociedade, desvelando a dimensão histórico-política das reformas de ensino, das concepções, dos projetos e das práticas formativas. (MANFREDI, 2002, p. 61).

A EP como um campo de pesquisa e não uma modalidade de ensino. Esse deve ser (e nesse evento é) o nosso investimento. Um campo de investigação que ainda é recente no Brasil. Mas, que ganha contornos com eventos como esse, o Colóquio Nacional - A produção do conhecimento 
em Educação Profissional, com o aumento de publicações em livros e revistas sobre EP, e a criação de Programas de Pós-Graduação, como o de Educação Profissional do IFRN, meu lugar de fala.

Mas, antes da configuração do campo de pesquisa, a Educação Profissional como modalidade de ensino tem sua (de)marcação, no Brasil, na Lei de Diretrizes e Bases da Educação Nacional, a qual integra-se aos diferentes níveis e as dimensões do trabalho, da ciência e da tecnologia, possibilitando a construção de diversos itinerários formativos.

Esses itinerários formativos remetem, na maioria das vezes, à relação histórica da educação com o trabalho. Conforme Saviani (2007, p. 154), o trabalho e a educação são atividades especificamente humanas, sendo o trabalho um processo essencialmente educativo, humanização.

Como uma forma à educação, podemos considerar que, a Educação Profissional se consolidou a partir da Revolução Industrial, pois com a crescente necessidade de produção, surgia também a necessidade de mão-de-obra especializada. (MANFREDI, 2002). Nesses termos, a Educação Profissional tem sua configuração associada a necessidade de formação para o trabalho, sendo à época da Revolução Industrial priorizado uma formação voltada ao trabalho manual em oposição ao trabalho intelectual.

Se a Educação Profissional tem sua configuração associada a necessidade de formação para o trabalho, poderíamos, aqui, escolher uma outra defesa: a de que o campo da EP é um desdobramento das discussões sobre educação e trabalho.

Considerando a historiografia brasileira e a presença das temáticas sobre EP nos eventos brasileiros, essa seria uma defesa pertinente. E, me levaria à discussão de como o campo da EP foi se configurando pelo diálogo e movimento junto a outros campos do conhecimento e conceitos. Um investimento alto para essa pesquisadora, nesse momento.

Por isso, vou a partir de agora dedicar-me ao estudo da produção do conhecimento em EP para, então, operar uma demarcação para esse campo no Brasil. Para isso, optei pelo mapeamento da produção sobre EP no Portal Capes.

Os mecanismos de busca que delimitaram as informações consideradas relevantes foram: o termo ou palavra-chave e o recorte temporal. Foram consideradas as publicações disponíveis no Portal Capes até o ano de 2014 e o termo educação profissional, com a utilização das aspas, que permitiu reduzir o quantitativo de dados considerados relevantes para a construção da pesquisa e por consequência, desconsiderar os dados irrelevantes. Portanto, com a definição destes pontos a documentação listada pelo Portal sobre a EP chegou a 517 artigos de periódicos que traziam em seus metadados o termo "educação profissional".

Realizada esta primeira etapa da pesquisa, inicia-se a segunda fase: a constituição de planilhas, através do Microsoft Office Excel, permitindo a reorganização e controle dos dados coletados. Para tal construção, ficando definido o título do artigo, o autor, o título do periódico, o ano de publicação, a fonte (coleção), o resumo e as palavras-chave, como principais campos a serem considerados. ${ }^{\text {ii }}$

Essas ações nos remetem à bibliometria que possibilitou o mapeamento do estado da arte, fornecendo um quadro dos temas de pesquisa que entusiasmam os pesquisadores, indicando variáveis atinentes a produção e a difusão do conhecimento. (VANTI, 2002). 
Logo após a transferência de todas estas informações para a planilha, chegamos à terceira fase do processo, aonde o quantitativo de 517 artigos chegou a ser reduzido para 237 (ver tabela 01), pois, muitos dos dados cadastrados no Portal Capes acham-se resumidos e/ou incompletos.

Quadro 01 - Artigos sobre EP disponíveis no Portal de Periódicos (1996-2014)

\begin{tabular}{|c|c|}
\hline ANO & ARTIGOS CIENTÍFICOS \\
\hline $\mathbf{1 9 9 6}$ & 01 \\
\hline $\mathbf{1 9 9 7}$ & 02 \\
\hline $\mathbf{1 9 9 8}$ & 01 \\
\hline $\mathbf{1 9 9 9}$ & 01 \\
\hline $\mathbf{2 0 0 0}$ & 05 \\
\hline $\mathbf{2 0 0 1}$ & 03 \\
\hline $\mathbf{2 0 0 2}$ & 04 \\
\hline $\mathbf{2 0 0 3}$ & 05 \\
\hline $\mathbf{2 0 0 4}$ & 08 \\
\hline $\mathbf{2 0 0 5}$ & 14 \\
\hline $\mathbf{2 0 0 6}$ & 12 \\
\hline $\mathbf{2 0 0 7}$ & 27 \\
\hline $\mathbf{2 0 0 8}$ & 18 \\
\hline $\mathbf{2 0 0 9}$ & 25 \\
\hline $\mathbf{2 0 1 0}$ & 21 \\
\hline $\mathbf{2 0 1 1}$ & 26 \\
\hline $\mathbf{2 0 1 2}$ & 31 \\
\hline $\mathbf{2 0 1 3}$ & 20 \\
\hline $\mathbf{2 0 1 4}$ & 13 \\
\hline Total & 237 \\
\hline & \\
\hline
\end{tabular}

Fonte: Elaboração própria, a partir dos dados estatísticos disponíveis no site do Portal.

Os anos com maior índice de publicação foram os de 2007, com 28 artigos publicados em periódico, e o ano de 2009 com a publicação de 29 artigos. A produção sobre EP no Brasil está sendo difundida em periódicos, principalmente, localizados na Região Sudeste, com um total de 54 periódicos listados e Região Sul com 18 periódicos indicados como divulgadores de artigos sobre EP. A Região Nordeste apresentou um número de 6 periódicos e a Região Centro-Oeste de 7 periódicos. Não foram listados artigos sobre EP difundidos em periódicos da Região Norte.

A produção do conhecimento sobre EP foi difundida, de 1996 a 2014, em 85 periódicos. Os periódicos com a maior presença de publicações voltadas à EP foram os seguintes:

Quadro 02 - Periódicos com maior número de publicações sobre EP disponíveis no Portal de Periódicos (19962014)

\begin{tabular}{|l|c|c|}
\hline \multicolumn{1}{|c|}{ REVISTA } & QUANT. & INSTITUIÇÕES VINCULADAS \\
\hline Trabalho, Educação e Saúde & 41 & Fiocruz \\
\hline Ciência \& Saúde Coletiva & 20 & ABRASCO \\
\hline Educação \& Sociedade & 12 & UNICAMP \\
\hline Ensaio - Avaliação de Políticas Públicas em Educação & 08 & Fundação CESGRANRIO \\
\hline Revista de Administração Contemporânea & 08 & ANPAD \\
\hline Cadernos de Pesquisa & 07 & UFMA \\
\hline Revista da Escola de Enfermagem da USP & 06 & USP \\
\hline Educação: Revista do Centro de Educação UFSM & 06 & UFSM \\
\hline Revista Thema & 05 & IFSul \\
\hline Educação e Pesquisa & 05 & USP \\
\hline
\end{tabular}

Fonte: Elaboração própria, a partir dos dados estatísticos disponíveis no site do Portal. 
O periódico com o maior número de artigos publicados sobre EP foi o "Trabalho, Educação e Saúde", com 41 artigos. Seguido do periódico "Ciência e Saúde Coletiva" com a publicação de 20 artigos. Esses dois periódicos concentram aproximadamente 25 por cento da produção sobre EP no Brasil. Pela especificidade da linha editorial dos periódicos, destacamos, assim, que a maioria das publicações são sobre EP no Brasil tem como tema a Educação Profissional em Saúde.

A maioria dos autores listados nas publicações são professores e pesquisadores ligados as instituições das Regiões Sudeste e Sul do Brasil - o que pode ser justificado pela concentração, no Brasil, de programas de pós-graduação e periódicos nessas Regiões, também.

No que concerne aos autores com maior número de publicações sobre EP nos periódicos no Portal Capes, constatamos que os pesquisadores Celso João Ferretti, Marise Nogueira Ramos e Gaudêncio Frigotto apresentam o maior número de artigos publicados, seja em produção individual ou em coautoria.

Quanto aos temas mais frequentes nas publicações de artigos sobre EP, encontram-se os referentes a: 1) Educação e trabalho; 2) Política pública ( Política Educacional. 3) Currículo; 4) PROEJA / Educação de jovens e adultos; 5) Formação de professores; 6) História da educação e 7) Ensino médio integrado. Como podemos observar no Quadro 3:

Quadro 3 - Temas mais frequentes nas publicações sobre EP em periódicos no Portal Capes (1996-2014)

\begin{tabular}{|l|c|c|}
\hline \multicolumn{1}{|c|}{ Temas } & No de artigos & Porcentagem \\
\hline Educação e trabalho & 27 & $11,95 \%$ \\
\hline Política pública / Política Educacional & 17 & $7,52 \%$ \\
\hline Currículo & 14 & $6,19 \%$ \\
\hline PROEJA / Educação de jovens e adultos & 7 & $3,10 \%$ \\
\hline Formação de professores & 6 & $2,65 \%$ \\
\hline História da educação & 5 & $2,21 \%$ \\
\hline Ensino médio integrado & 3 & $1,33 \%$ \\
\hline
\end{tabular}

Fonte: Elaboração própria, a partir dos dados estatísticos disponíveis no site do Portal.

O tema "educação e trabalho" fora mapeado como o mais frequente nas publicações referentes a EP no Brasil. Esse resultado está associado a hipótese, anteriormente citada, de que o campo da EP vem se configurando a partir do eixo investigativo Educação e Trabalho. Como asseverou Ramos (2013, p. 39),

[...] a produção do conhecimento em educação e na educação profissional e tecnológica implica buscar compreender a história da (de)formação dos trabalhadores a partir do desenvolvimento material da existência humana, tendo o trabalho como mediação fundamental e a sua relação com a ciência e com a cultura.

Dessa maneira, podemos considerar que o campo da EP no Brasil vem se configurando pelas inter-relações de temáticas como educação e trabalho na leitura da EP como modalidade de ensino e espaço de disputas políticas.

E mais, o campo da EP no Brasil vem ganhando novos contornos com objetos e temas provenientes das transformações históricas vinculadas as políticas públicas voltadas à EP. Nesses termos, essas são considerações em trânsito. Muitas indagações ainda me animam à pesquisa. $E$, em outras oportunidades espero dialogarmos sobre a (re)constituição do campo da EP no Brasil. 


\section{REFERÊNCIAS BIBLIOGRÁFICAS}

1. BOURDIEU, P. O campo científico. In: ORTIZ, R. (Org.). Pierre Bourdieu: sociologia. São Paulo: Ática, 1983. p. 122-155. (Grandes cientistas sociais, 39).

2. ELIAS, Norbert. A sociedade dos indivíduos. Rio de Janeiro: Zahar Editora, 1994.

3. MANFREDI, Sílvia M. Educação profissional no Brasil. São Paulo: Cortez, 2002.

4. PORTAL de Periódicos Capes/MEC. Disponível em: < http://www.periodicos.capes.gov.br/ > Acesso em: 12 maio. 2015.

5. RAMOS, Marise Nogueira. Trabalho e educação: implicações para a produção do conhecimento em Educação Profissional. In: MOURA, Dante Henrique. (Org.). Produção de conhecimento, políticas públicas e formação docente em educação profissional. Campinas, SP: Mercado de Letras, 2013. p. 23-40.

6. VANTI, Nadia Aurora Peres. Da bibliometria à webliometria: uma exploração conceitual dos mecanismos utilizados para medir o registro da informação e o avanço do conhecimento. Ciência da Informação, v. 31, n.2, p.152-162, maio/ago.2002.

\section{Notas:}

\footnotetext{
' Esse texto foi apresentado na Mesa-redonda A produção do conhecimento e a configuração do campo da educação profissional por ocasião do III Colóquio Nacional A produção do conhecimento em Educação Profissional, no dia 6 de agosto de 2015, realizado no Instituto Federal do Rio Grande do Norte/Campus Natal - Central. Da referida mesa também participaram os professores Maria Ciavatta (UFF) e Gabriel Grabowski (Feevale).

ii É importante ressaltar que nesta etapa, alguns artigos traziam dados incompletos, como por exemplo, a ausência de resumos, e como isso foi necessária à busca em outras fontes secundárias a fim de não deixar lacunas na pesquisa.
} 